\title{
A STUDY FOR REMOTE DETECTION OF INDUSTRIAL EFFLUENTS' EFFECT ON RICE USING THERMAL IMAGES
}

\author{
S. Dehnavi ${ }^{\text {a, }}{ }^{\text {, }}$ A.A. Abkar ${ }^{\text {a }}$, Y. Maghsoudi ${ }^{\text {a }}$, E. Dehnavi ${ }^{\text {b }}$ \\ ${ }^{a}$ Geodesy and Geomatics Engineering Faculty, K.N.Toosi University of Technology, Tehran, Iran - (s_dehnavi@mail., abkar@, \\ ymaghsoudi@)kntu.ac.ir \\ ${ }^{\mathrm{b}}$ R\&D, No.2, $1^{\text {st }}$ St., Makhsous Rd., Tehran, Iran - (e.dehnavi@kohantajkimiya.com)
}

KEY WORDS: Thermal remote sensing, Rice, Industrial effluent, temperature.

\begin{abstract}
:
Rice is one of the most important nutritious grains all over the world, so that only in some parts of Asia more than 300 million acres allocated for cultivating this product. Therefore, qualitative and quantitative management of this product is of great importance in commercial, political and financial viewpoints. Rice plant is very influenced by physical and chemical characteristics of irrigation water, due to its specific kind of planting method. Hence, chemically-polluted waters which received by plant can change in live plants and their products. Thus, a very high degree of treatment will be required if the effluent discharges to rice plants. Current waters receive a variety of land-based water pollutants ranging from industrial wastes to excess sediments. One of the most hazardous wastes are chemicals that are toxic. Some factories discharge their effluents directly into a water body. So, what would happen for rice plant or its product if this polluted water flow to paddies? Is there any remotely-based method to study for this effect? Are surface temperature distributions (thermal images) useful in this context? The first goal in this research is thus to investigate the effect of a simulated textile factory's effluent sample on the rice product. The second goal is to investigate whether the polluted plant can be identified by means of thermal remote sensing or not. The results of this laboratory research have proven that the presence of industrial wastewater cause a decrease in plant's product and its f-cover value, also some changes in radiant temperature.
\end{abstract}

\section{INTRODUCTION}

Industrial wastes are major sources of pollution in all environments and require on-site treatment before discharge into sewage system. Soil and plants are under tremendous pressure due to discharge of effluents. Very few are aware of this discharging, a globally important issue (Emongor, Nkegbe et al. 2005). Department of Environment (DOE), recently identified 900 large polluting industries, which have no treatment facilities for effluents and wastes (M.O. Islam, Md.H.R. Khan et al. 2006). These heavily toxic effluents were discharging directly to adjacent soils and rivers (Khan 2006). In the production process of these industries a lot of solid, semisolid and liquid wastes are generated that may contain substantial amount of toxic organic and inorganic pollutants, and if dumped in the environment without treatment then this may lead to serious environmental consequences. This will also undoubtedly deteriorate soil productivity and adversely affect crop production in the surrounding land. As discussed in (Shukry 2001), industrial effluents had remarkable changes in the distribution of ions and their concentrations in wheat and bean plants. Unfortunately, there is little work on this waste material and wastewater in relation to their use in agriculture or discharge to agricultural land (M.O. Islam, Md.H.R. Khan et al. 2006).

Moreover, nearby some of rice paddies in Iran (e.g. Guilan province) there are some factories whereby textile dyeing process takes place. Consequently some wastes (poisonous at certain levels), contaminate the surrounding cultivable lands.
Against this background, the objectives of the present study were to evaluate the extent and impacts of the discharging industrial effluents on the growth, yield and nutrition of rice.

This work is prepared on the basis of a laboratory test done in a small greenhouse and it is anticipated that the results might be helpful for future researches in this context. The main idea of this research was to see if it is possible to investigate whether a plant which was irrigated by polluted water can be discriminated remotely from images. The structure of the rest of this paper is as follows. In section 2, materials and the planned experimental set up is elaborated. Section 3 briefly describes the measurements done in our experiment. Results and experiments are reported in section 4, while we draw our conclusion in section 5 .

\section{MATERIALS AND EXPERIMENTAL SET UP}

The study was done in a greenhouse which was designed in Tehran south, Iran and on rice samples were irrigated with simulated effluents of a textile dyeing factory, in the whole period of their growth stage. Information on the understudy rice samples, experimental set up and effluents' chemical structure are discussed with great detail in the next few subsections.

\subsection{Rice Samples}

Rice seedlings were gathered carefully from Rasht, Guilan and were transferred to the prepared greenhouse in Tehran. Samples were ready for planting and they have spent their initial phases

\footnotetext{
* Corresponding author
} 
of their growth in wet nursery. 30-day old seedlings were transferred to sterilized soil, with puddled soil flooded with 3-5 $\mathrm{cm}$ of standing water. The characteristics of the seedlings are provided in Table 1 .

Table 1: Rice seedlings characteristics

\begin{tabular}{|l|c|}
\hline Variety type & Native \\
\hline Rice type & Tarom Hashemi (Sadri group) \\
\hline Nursery & Traditional \\
\hline Seeding date & 8 May 2012 \\
\hline Initial height & $49 \mathrm{~cm}$ \\
\hline Seedling type & Ripen \\
\hline
\end{tabular}

Figure 1, represents the prepared seedlings.

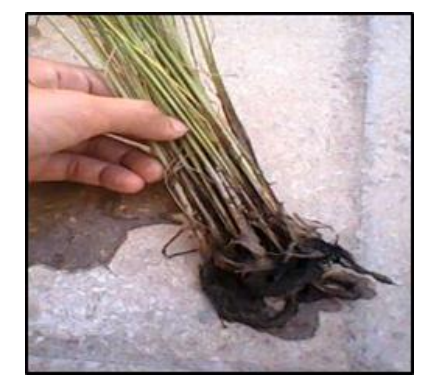

Figure 1: Prepared ripen seedlings

\subsection{Experimental set up}

Impact of the effluents on the irrigated plants was investigated using the following research plan. First of all, the seedlings were planted into two similar pots (with size $63 \times 30 \times 63 \mathrm{~cm}^{3}$ ). Next, one of the pots was chosen as the test sample and the other was selected as the control sample. Afterwards, the test sample was irrigated with polluted water while it was not true for the control one. Except the mentioned point, the other life and treatment conditions (i.e. time of irrigation, temperature, relative humidity, sun radiation, wind blow, fertilizing, etc.) were totally similar for both samples. This situation makes the analysis on effluents effects far more feasible. In the next step, data acquisition was synchronized with Terra and Aqua sensors' local overpass (10:30 a.m. and 22:30 p.m. respectively). Hence, this synchronization to MODIS, make similar studies like this much more feasible than before. It is worth mentioning that in addition to this synchronization, time of acquisitions was determined considering the thermal crossover times (Alavi panah 1387).

\subsection{Simulation of industrial effluents}

The applied effluent in this research was simulated from the first step dyeing process of a textile material, and its compositions are as below mentioned (Shams Nateri, Dehnavi et al. 1391).

2.3.1. Sodium Chloride (NaCl): The simulated effluent salinity was increased with $\mathrm{NaCl}$ to make saline treatments. However, rice is a very powerful plant against the soil salinity (Amiri Larigani 1390), thus it was anticipated that this material had the least effect on the growth stage.

2.3.2. Direct Red, Yellow and Blue dye: Structure of other applied dyes in colour index represents in below figures.

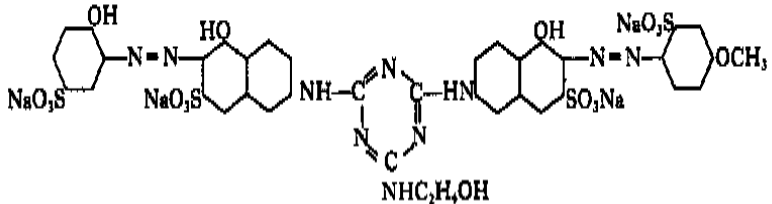

Figure 2: Direct Red BWS (243) (Shams Nateri, Dehnavi et al. 1391)

\section{C.I. Diroot Yellow 86 (Bright Reddinh Yellow)} Seigo Fujoka and Sadaharu Abeta,
Dyes and Pigments 3 (1982) 281

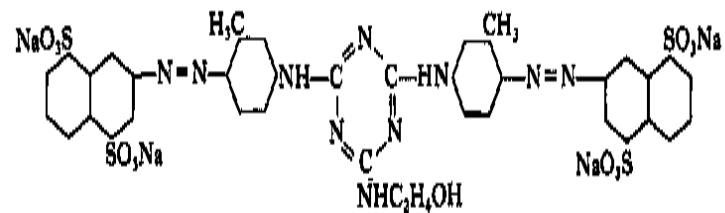

Figure 3: Direct Yellow RL (86) (Shams Nateri, Dehnavi et al. 1391)<smiles>COc1cc(-c2ccc(N=Nc3c(O)c(S(=O)(=O)[O-])cc4cc(S(=O)(=O)O)ccc34)c(OC)c2)ccc1N=Nc1c(O)c(S(N)(=O)=O)cc2cc(Nc3ccccc3)ccc12</smiles>

Figure 4: Direct Blue BRL(201) (Shams Nateri, Dehnavi et al. 1391)

\section{MEASUREMENT PLAN}

Effective parameters on plant growth in its growth stages such as temperature and relative humidity as well as the thermal field images were recorded as statistical information during the sample phenological stages. The measurement planning cycle consists of the following stages:

\subsection{Temperature and relative humidity}

Temperature and relative humidity of the greenhouse was permanently measured and recorded at least two times a day (10:30 a.m. and 22:30 p.m.) during the whole growth stage. These records throughout the entire period are shown in both day and night respectively in Appendix A (Figures 16-19).

\subsection{FLIR and RGB image field acquisitions}

In order to record the Infrared spectra of the understudy samples, the FLIRi5 (Components 2015) handheld system was used. The sensor was adjusted to acquire surface temperature and to record the average value of the target surface simultaneously. FLIRi5 sensor characteristics are provided in Table 2 .

Table 2: FLIRi5 Sensor Characteristics

\begin{tabular}{|c|c|}
\hline \multicolumn{2}{|c|}{ Geometrical and imaginal } \\
\hline Field Of View & $16.8 \times 16.8$ \\
\hline
\end{tabular}




\begin{tabular}{|c|c|}
\hline Focal Length & $6.76 \mathrm{~mm}$ \\
Spatial Resolution & $3.7 \mathrm{mrad}$ \\
Temperature sensitivity & $0.1^{\circ} \mathrm{C}$ \\
Focusing & Free \\
\hline \multicolumn{2}{|c|}{ Detector Characteristics } \\
\hline Detector type & MicroBolometer \\
Spectral Range & $7.5-13$ Micrometers \\
IR image resolution & $80 \times 80$ pixels \\
\hline \multicolumn{2}{|c|}{ Measurement } \\
\hline Temperature range & -20 to $250^{\circ} \mathrm{C}$ \\
Accuracy & $\pm 2^{\circ}$ \\
\hline \multicolumn{2}{|c|}{ Camera } \\
\hline Size & $223 \times 79 \times 83 \mathrm{~mm}$ \\
\end{tabular}

A Schematic view of the FLIRi5 is presented in Figure 5.

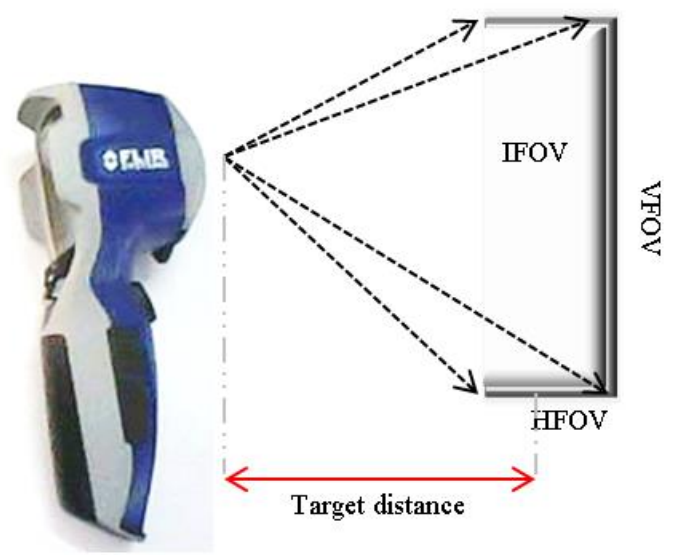

Figure 5: FLIRi5 sensor

The emissivity coefficient was adjusted to 0.95 for a mixture of wet soil and vegetation cover based on the available Look Up Tables. Considering the vase sizes and nominal field of view of the sensor, nadir measurements were done in both 0.5 and 1 meter (Table 2 and Figures 6 and 7).

Table 3: Nominal FOV and measurement heights

\begin{tabular}{|c|c|}
\hline Height $(\mathbf{m})$ & IFOV $(\mathbf{m m})$ \\
\hline 0.5 & 1.85 \\
\hline 1 & 3.7 \\
\hline
\end{tabular}
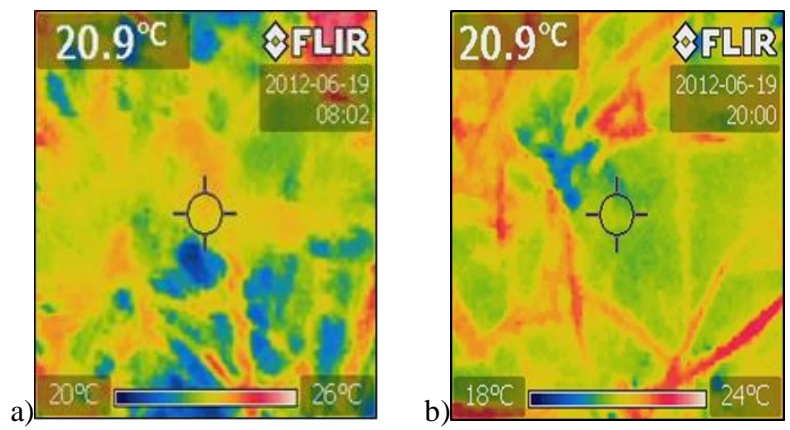

Figure 6: Nadir FLIR measurement of control sample; a) Daytime measurements, b) Nighttime measurement
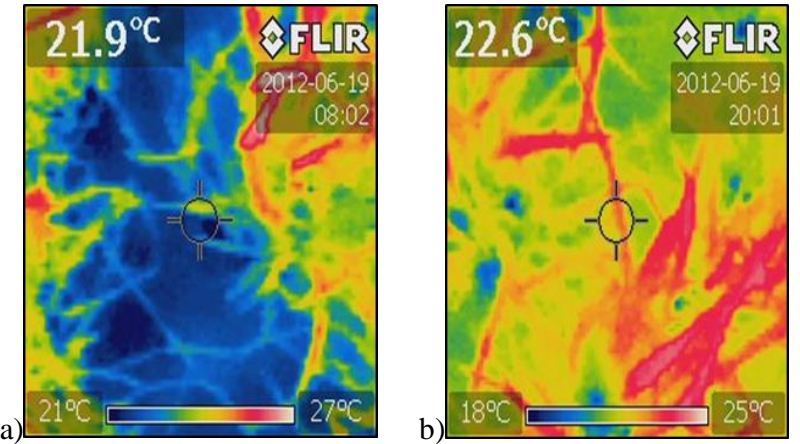

Figure 7: Nadir FLIR measurement of under test sample; a) Daytime measurements, b) Nighttime measurement

On the top left corner of each image the average surface temperature of the samples are shown. Moreover the gradient temperature scale bar is provided in the lower part of each image, and the minimum and maximum values are shown respectively in left and right part of this scale bar.

RGB images were also taken in a nadir status and in similar heights as above-mentioned (Figure 8).
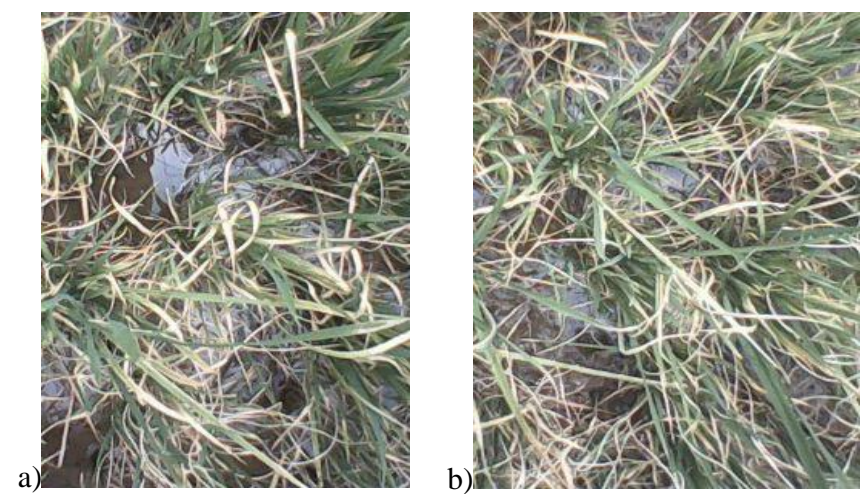

Figure 8: Rice samples; a) control, b) test. Images were taken in $19^{\text {th }}$ June 2012 , Rice samples were in their booting stage at that time.

\section{EXPERIMENTAL RESULTS}

There are two methods for the analysis of the productivity and performance of each sample. First, rice plant performance can be evaluated using well-known statistical approaches which are introduced with great detail below. Second, the f-cover values of samples can be extracted and analyzed applying the RGB images. Moreover, the average temperatures are investigated in the critical stages of their growth.

\subsection{Rice plant performance components}

The performance of rice samples can be compared after the harvesting. Therefore, the method for this performance analysis is elaborated in the following paragraphs.

4.1.1. Number of panicles in Canopy and number of seeds in panicles: Number of panicles and their seeds were counted for both samples (Table 4).

4.1.2. Thousand-grain weight: Thousand-grain weight (TGW) was recorded as the main rice yield component after harvesting. Three $5 \mathrm{gm}$ batches of both hollow and solid grains were provided. In order to this discrimination, samples were poured 
in a bottle of water (Figure 9.e). Then, the number of solid grains was counted in a $5 \mathrm{gm}$ batch. Finally, the TGW was determined for each sample using a ratio analysis (Table 4).

4.1.3. Grain weight per unit area: Weight of grains per unit area can be calculated using the Equation 1 (Appendix A).

Table 4: Rice sample's performance

\begin{tabular}{|l|c|c|}
\hline & Test sample & Control sample \\
\hline $\begin{array}{l}\text { No. of panicles in } \\
\text { canopy }\end{array}$ & 29 & 28 \\
\hline No. of grains in & 261 & 223 \\
\hline Solid grains (\%) & 37.93 & 49.78 \\
\hline $\begin{array}{l}\text { Thousand-grain } \\
\text { weight }\end{array}$ & 12.92 & 14.451 \\
\hline $\begin{array}{l}\text { Grain weight per } \\
\text { unit area }\end{array}$ & 4.9 & 18.27 \\
\hline
\end{tabular}

4.1.4. Dry and wet weights of paddies: One of the effective and important parameters in the analysis of plant health and its performance is determining the moisture content. Therefore, after the harvesting, paddies were weighted. Afterwards, they were dried slowly in oven, in 70-80 degree celcius, and were weighted again. Drying process is shown in Figure 9 and measured weights are presented in Table 5 .

Table 5: Soil moisture content in paddies

\begin{tabular}{|l|c|c|}
\hline & Test treatment & Control treatment \\
\hline $\begin{array}{l}\text { Panicle's Dry } \\
\text { weight (gr) }\end{array}$ & 17.04 & 17.04 \\
\hline $\begin{array}{l}\text { Panicle's wet } \\
\text { weight (gr) }\end{array}$ & 23.04 & 19.04 \\
\hline $\begin{array}{l}\text { Moisture content } \\
(\%)\end{array}$ & 17.54 & 12.76 \\
\hline
\end{tabular}

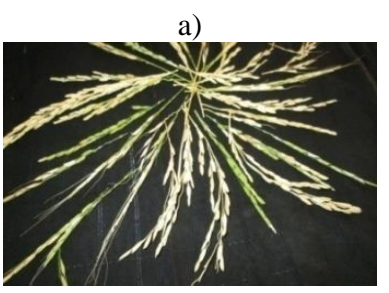

c)

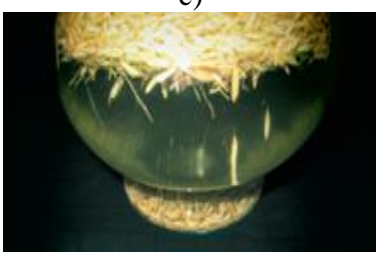

e)

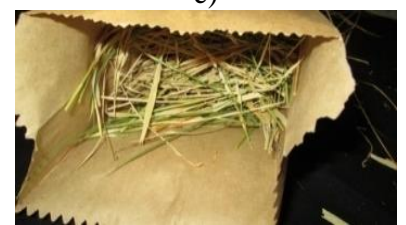

b)

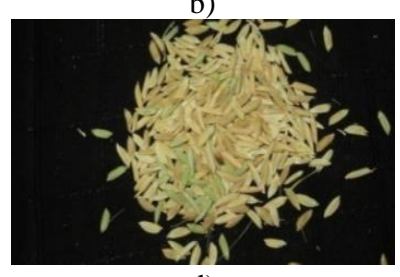

d)

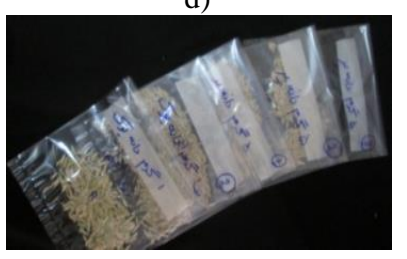

f)

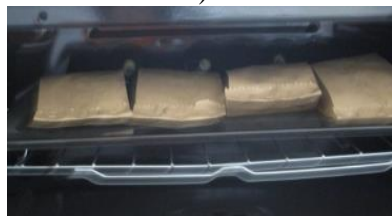

Figure 9: Performance analysis of harvested samples; a) No. of panicles in canopy, b) No. of grains in panicles, c) Discrimination of solid and hollow grains in a bottle of water, d,e) Drying paddies in oven.

\subsection{F-Cover determination}

The vegetation cover was estimated for both samples from RGB images in their entire growth stages. For this purpose, the classification was performed on RGB images and the f-cover value was calculated from the classified image. Figure 10, presents the classified image of the healthy sample.
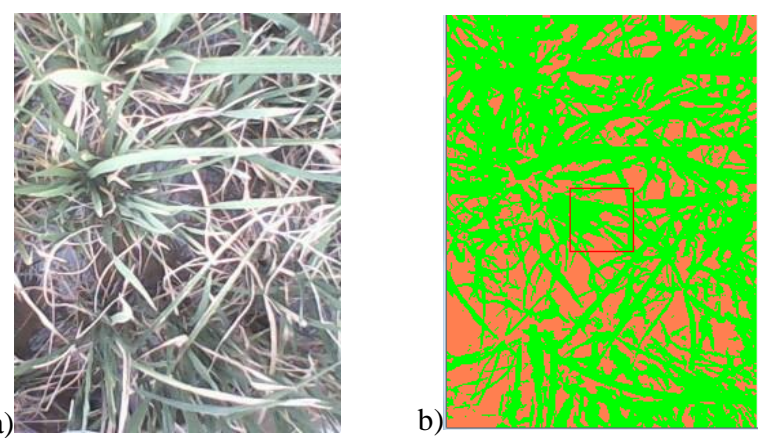

Figure 10: f-cover value estimation from the RGB image of healthy sample in its flowering stage; a)RGB image, b)classified image.

\subsection{Results}

4.3.1. f-cover percentage: Comparison of the f-cover values for both samples in their critical growth stages (i.e. panicle initiation, booting, heading, and flowering) have shown that, this value was higher in most cases for the control sample (Figure 11). This is a reason for the effectivity of test sample from industrial effluents, so that the f-cover value and the harvestable rice have decreased in this sample.

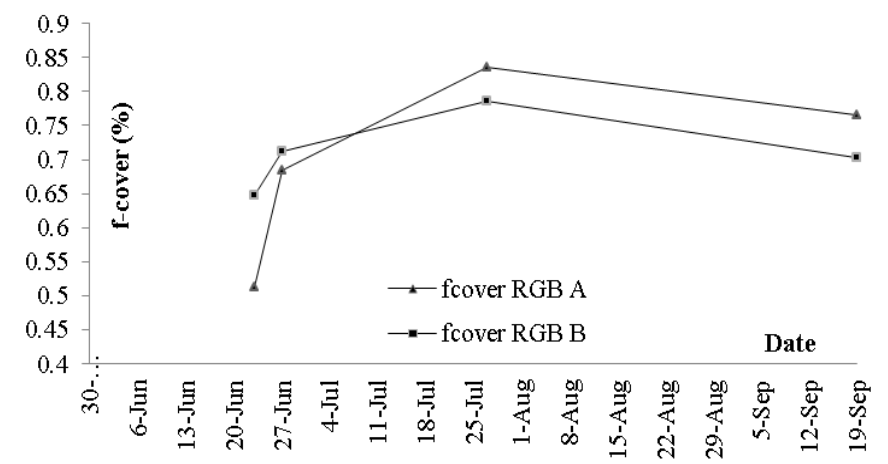

Figure 11: The f-cover percent in two treatments (A: control, B: test) and in their critical growth stages.

4.3.2. Averaged surface temperature changes: Study on the surface temperature of the two treatments in their critical growth stages has shown that day/night temperature differences were lower in the control sample. This means that the thermal equilibrium was higher in that sample. It is also worth noticing that the test sample has absorbed more energy during daylight (Figures 12 and 13). It is clear that reducing in energy absorption of test sample affect the net photosynthesis. 


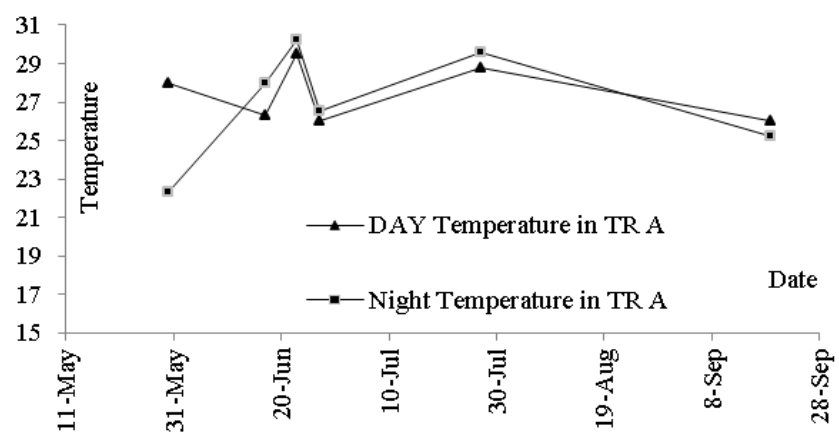

Figure 12: Averaged surface temperatures in control sample (treatment A), in day and night time

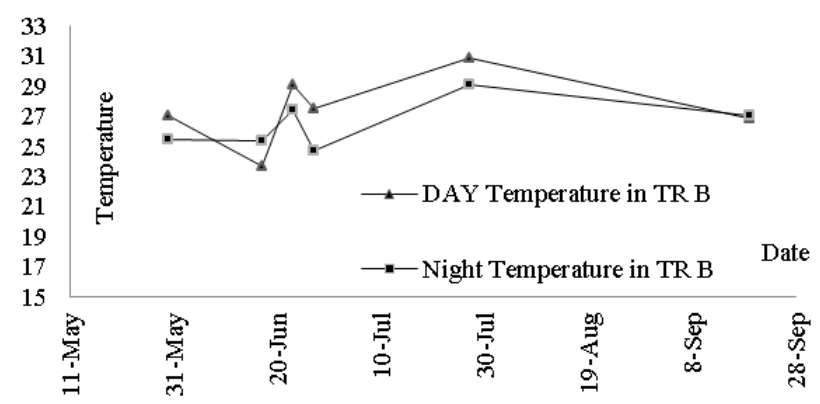

Figure 13: Averaged surface temperatures in test sample (treatment B), in day and night time

Besides, differences in treatment temperatures in both day- and nighttime are informative (Figures 14 and 15).

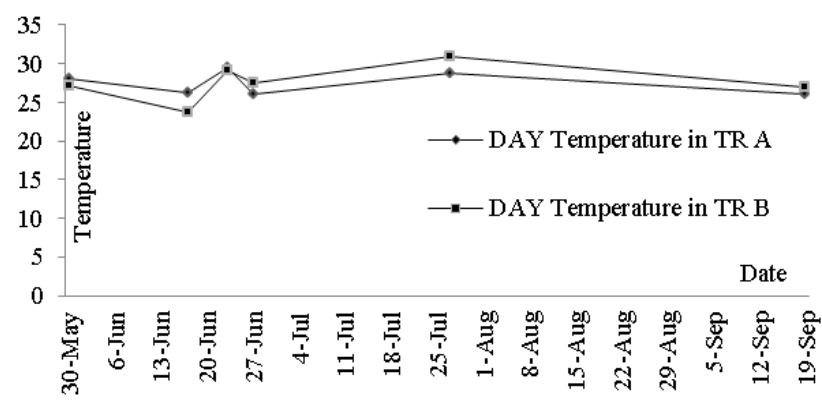

Figure 14: Averaged surface temperature of both treatments in daytime

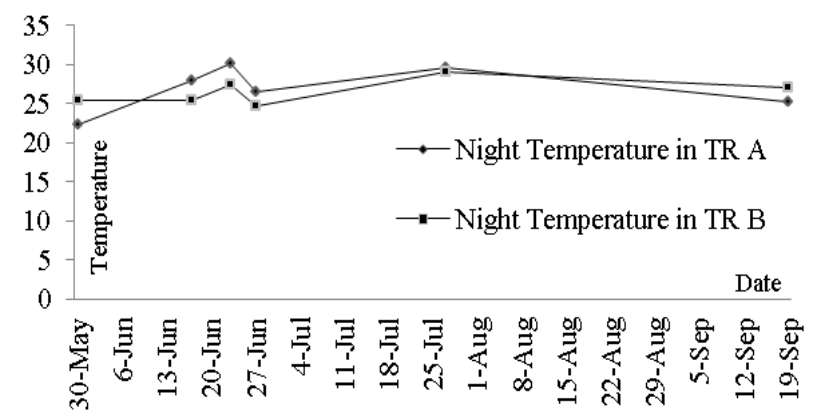

Figure 15: Averaged surface temperature of both treatments in nighttime

As can be seen, in most cases the surface temperature of control sample was lower during the daytime and it was higher in nighttime. In fact the presence of industrial effluents causes a decrease in energy absorption of the test sample during the day.
Therefore, it is not surprising that effluents affect the photosynthetic procedure of the rice plant and the final products.

\subsubsection{Field Observations}

The most highly significant of the field observations was the irregularities in phenological stages of the test sample after addition of effluents. These changes are as follows:

Earrings of the control sample were higher in number and also in strength.

- $\quad$ Panicle initiation was earlier in control sample.

The flowering stage was earlier in control sample.

\section{CONCLUSION}

Rice plant is very influenced by physical and chemical characteristics of irrigation water, due to its specific kind of planting method. Hence, chemically-polluted waters which received by plant can change in live plants and their products. Although, rice plants are under tremendous pressure due to discharge of effluents, very few are aware of this discharging, a globally important issue. Therefore, this research was done in a laboratory level to see whether there is any specific change in toxic sample or not, especially in its temperature distributions, as a result of toxic irrigating.

The results presented here have shown that, the presence of toxic industrial effluents in the irrigating water causes some disorderliness in phenological stages of the test sample. Moreover, the harvested product decreased by 14 percent and the f-cover value declined by approximately 6 percent. The research also showed some changes in the temperature distribution of toxic sample.

Although this study found significant results, research is still relatively limited and there is a long way to go. Therefore, study on the large-scale rice paddies, on the thermal gradients of the thermal images, and also in the whole growth stages is proposed to be investigated in the near future.

\section{ACKNOWLEDGEMENTS}

Authors would like to thank Dr Bahman Amiri Larijani, for his expert advice and his generosity with his time and knowledge.

\section{REFERENCES}

Alavi panah, S. K. ( 1387). Thermal Remote sensing and its Application in earth sciences. Tehran, Iran, Tehran university press Institute.

Amiri Larigani, B. (1390). Support system for evaluating Rice product loss using RS \& GIS and ORYZA 2000 growth model. a. g. o. A. r. center. Amol.

Components, A. (2015). User's manual FLIR ix series.

Emongor, V., E. Nkegbe, B. Kealotswe, I. Koorapetse, S. Sankwasa and S. Keikanetswe (2005). "Pollution indicators in Gaborone industrial effluent." Journal of Applied Sciences 5(1): 147-150.

Khan, H. (2006). "Assessment of SPWAC (Soil-Plant-WaterAir Continuum) Quality within and around Dhaka City." Report submitted to the Director of the centre for Advanced Studies and Research in Biotechnological Sciences, University of Dhaka, Bangladesh. 
M.O. Islam, Md.H.R. Khan, A.K. Das, M.S. Akhtar, Y. Oki and T. Adachi2 (2006). "Impacts of industrial effluents on plant growth and soil properties." Soil \& Environ 25(2): 113-118.

Shams Nateri, A., E. Dehnavi and E. Zahedi (1391). Investigating salt effect on absorption behavior of direct dye. $\underline{\text { 8th national lecture on textile engineering, }}$. Yazd university.
Shukry, W. M. (2001). "The effect of industrial effluents and vesicular-arbuscular mycorrhizae on nutrient distribution and concentration of wheat and bean plants." OnLine Journal of Biological Sciences 1(8): 689-693.

APPENDIX (A)

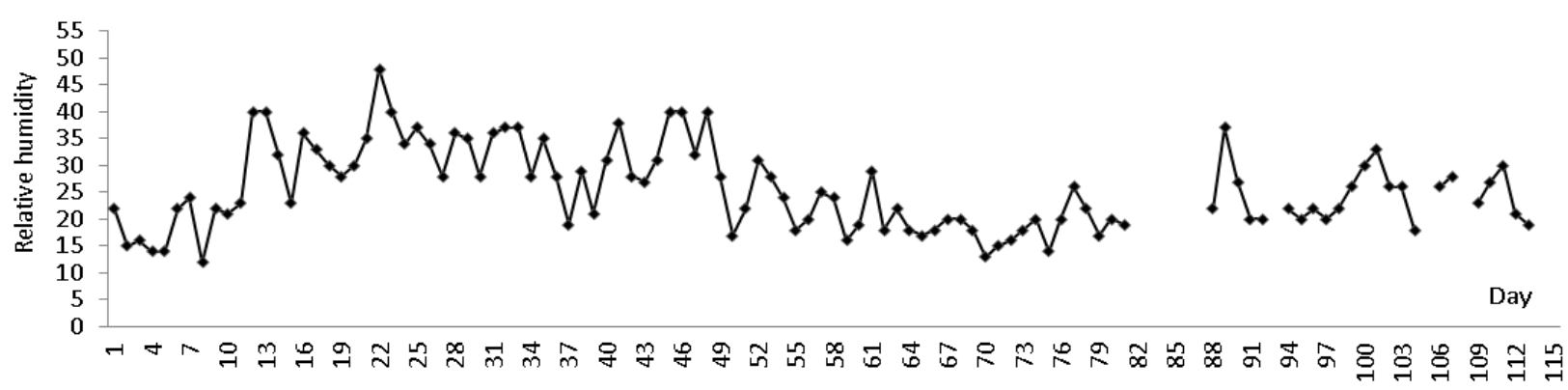

Figure 16: Daytime Relative humidity measured by data logger

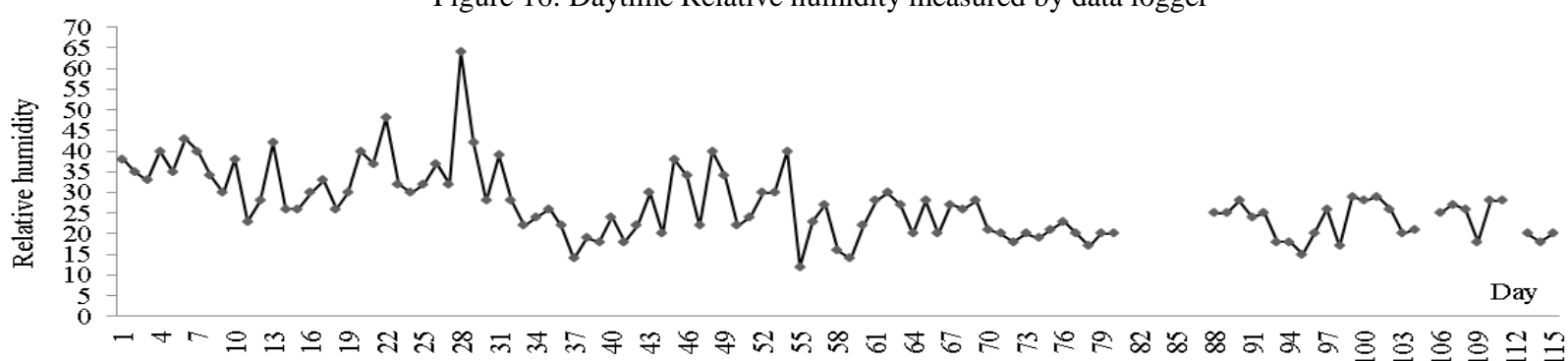

Figure 17: Nighttime Relative humidity measured by data logger

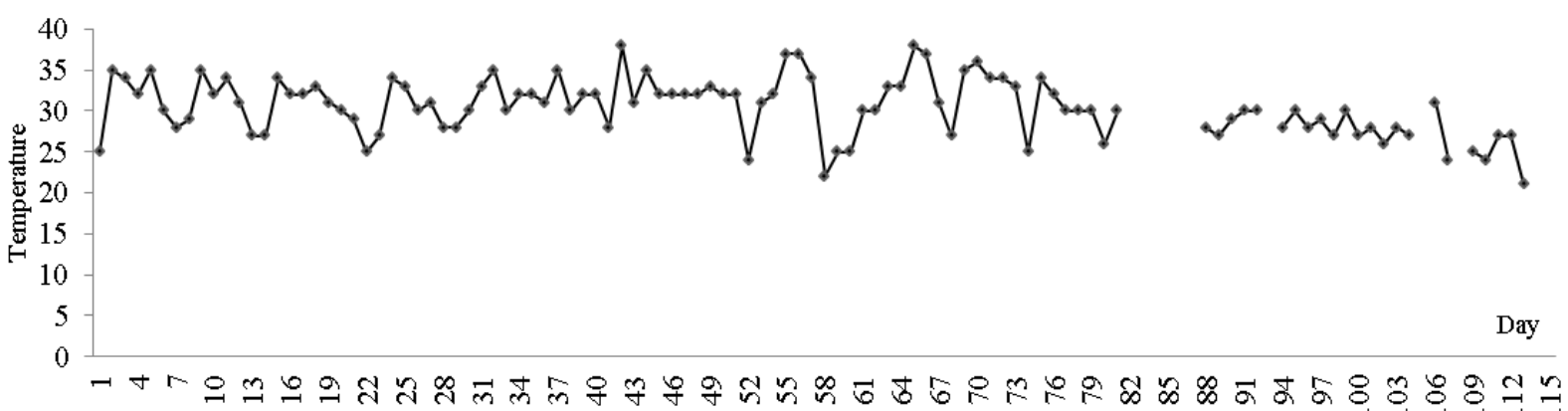

Figure 18: Daytime temperature measured by data

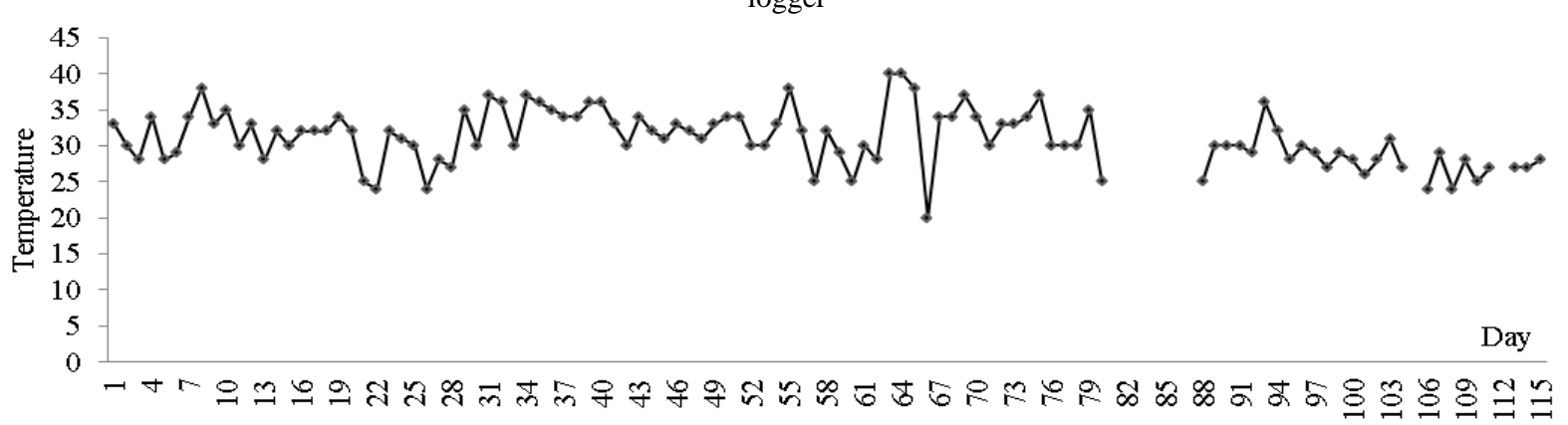

Figure 19: Nighttime temperature measured by data logger

\section{Equation 1:}

Grain weight per unit area $\left(\frac{\mathrm{g}}{\mathrm{m}^{2}}\right)$

(No. of canopies in $m^{2} \times$ No. of panicles in $m^{2} \times$ No. of grains in canopy $\times$ Panicle $\% \times$ Thousand grain weight) 